Geopolítica(s) Revista de estudios sobre espacio y poder ISSN: 2172-3958

https://dx.doi.org/10.5209/geop.62938

\title{
Geopolítica y desarrollo: una mirada a partir del transporte ferroviario en países sudamericanos en el siglo XXI
}

\author{
Alejandro Rascovan ${ }^{1}$ \\ Recibido: 2 de enero de 2019/ Aceptado: 24 de noviembre de 2020
}

Resumen. ¿Para qué sirve la infraestructura en transporte? ¿Por qué la idea de construir ferrocarriles sigue, en las primeras décadas del siglo XXI, tan presente como hace 150 años? Desde la formación de los Estados-nación modernos en Sudamérica el modelo de desarrollo económico/territorial y sus políticas institucionales se encuentran en el centro de los debates políticos. A partir de esta premisa y centrándose en los ferrocarriles internacionales se analizan diversas perspectivas sobre aquellos modelos. La concreción casi nula de líneas internacionales resulta significativa en comparación con el lugar que ocupa en discursos e instituciones internacionales. Con punto de partida en la I Reunión de Presidentes de América del Sur (2000) - y, recorriendo la experiencia de la UNASUR, el MERCOSUR, la IIRSA y el COSIPLAN_- retomamos discursos de gobernantes y otras fuentes institucionales para dar cuenta del estrecho vínculo entre infraestructura ferroviaria y desarrollo y las representaciones geopolíticas que conllevan.

Palabras clave: ferrocarriles; UNASUR; integración regional; geopolítica; desarrollo; MERCOSUR; IIRSA; COSIPLAN.

\section{[en] Geopolitics and Development: Insights into Railway Transportation in South American Countries in the 21st Century}

\begin{abstract}
What does transportation infrastructure serve for? Why does the idea of building railways, in the first decades of the 21 st century, remains actual after 150 years? Since the formation of modern nation-states in South America, the economic-territorial development models and its policies are at the core of political debates. Following this premise and, with focus on international railways, several perspectives on those models are analysed. The almost null conclusion of those plans is significant considering the attention given to the matter by political discourses and international institutions. Starting from the 1st South American Presidents Meeting (2000) - and including the Union of South American Nations (UNASUR), the Southern Common Market (MERCOSUR) and IIRSA and COSIPLAN -, we recover discourses from rulers and other institutional sources in order to explain the close link between railway infrastructure, development and geopolitical representations.
\end{abstract}

Keywords: railways; UNASUR; regional integration; geopolitics; development; MERCOSUR; IIRSA; COSIPLAN.

1 Facultad de Ciencias Sociales (Universidad de Buenos Aires) y Grupo de Estudios Sobre Fronteras y Regiones (GEFRE), Facultad de Filosofía y Letras (UBA), Argentina.

Email: alejandrorascovan@gmail.com

https://orcid.org/0000-0002-5832-883X 


\section{[pt] Geopolítica e desenvolvimento: um olhar a partir do transporte ferroviário na América do Sul no século XXI}

Resumo. Para que serve a infraestrutura em transporte? Por que a ideia de construir ferrovias continua,
nas primeiras décadas do século XXI, ainda presente como há 150 anos? Desde a formação dos Estados-
nação modernos na América do Sul, os modelos de desenvolvimento econômico/territorial e suas polí-
ticas institucionais estão no centro dos debates políticos. A partir desta premissa e tomando como centro
as ferrovias internacionais, analisam-se diversas perspectivas sobre tais modelos. A construção quase
inexistente de ferrovias internacionais se torna significativa quando comparada ao lugar que elas ocu-
pam nos discursos e nas instituições internacionais. Tendo como ponto de partida I Cúpula Sul-Ameri-
cana (2000) - e atravessando as experiências da UNASUL, MERCOSUL, IIRSA e COSIPLAN -, re-
tomamos os discursos dos governantes e outras fontes institucionais para apresentar o vinculo estreito
entre a infraestrutura das ferrovias, desenvolvimento e as representações geopolíticas subjacentes. Palavras-chave: ferrovias; UNASUR; integração regional; geopolítica; desenvolvimento; MERCOSUR; IIRSA; COSIPLAN.

Sumario. Introducción. 1. Marco teórico. 1.1. Desarrollo e integración regional. 2. Actualidad y proyectos ferroviarios en América del Sur. 2.1. Breve historia de los ferrocarriles internacionales en América del Sur. 2.2. IIRSA/COSIPLAN y el futuro del ferrocarril. 2.3. Los organismos internacionales de crédito y la integración regional. Conclusiones. Agradecimientos. Referencias.

Cómo citar: Rascovan, A. (2021). Geopolítica y desarrollo: una mirada a partir del transporte ferroviario en países sudamericanos en el siglo XXI. Geopolítica(s). Revista de estudios sobre espacio y poder, 12(1), 23-50. https://dx.doi.org/10.5209/geop.62938

\section{Introducción}

Una de las cuestiones más controversiales desde la formación de los Estados nacionales en Sudamérica hasta la actualidad ha sido su modelo de desarrollo económico/territorial y las políticas institucionales y relaciones sociales necesarias para llevarlo a cabo. Esta constante se mantiene hasta la actualidad, mutando con el cambio de los gobiernos que reorientan sus políticas de acuerdo a sus necesidades e intereses. Planteamos un análisis geopolítico de los modelos de desarrollo económico/territorial propuestos por diversos actores políticos, tomando como caso los ferrocarriles internacionales, para dar cuenta de una pluralidad de sentidos políticos conflictivos acerca del vínculo entre los países de América del Sur entre sí y con los imaginarios que construyen sobre el lugar de la región en el mundo.

¿Para qué sirve la infraestructura en transporte? Krüger señala:

Los objetos, las personas, las cargas o la información a transportar se mueven de forma activa o pasiva a lo largo de ejes de una red que a su vez forma parte de la infraestructura de transporte. El transporte surge de la necesidad de moverse en el espacio, generada por la separación física de los lugares de las actividades humanas (2018, p.179).

En paralelo, Blanco (2018, p.154) agrega que "las redes así configuradas se producen y reproducen a partir de su uso social". 
La experiencia dispar en cada país de los ferrocarriles sudamericanos no contrasta con la concreción casi nula de líneas internacionales. Sin embargo, a pesar de su escaso número, ocupan un lugar significativo en tanto que se asocia su construcción y funcionamiento al desarrollo económico entendido como éxito.

El objetivo principal de este artículo es identificar el vínculo existente entre geopolítica y desarrollo económico/territorial en los ferrocarriles internacionales en Sudamérica (actuales y propuestos) entre el año 2000, que es cuando se celebra la I Reunión de Presidentes de América del Sur y el año 2018 cuando Argentina, Brasil, Chile, Colombia, Paraguay y Perú abandonan la Unión de Naciones Suramericanas (UNASUR). Para esto, dividimos el trabajo en dos secciones. En la primera retomamos la voz de los actores/as de la academia y de la política en relación al desarrollo económico/territorial y la construcción de ferrocarriles. Esta sección está conformada por la revisión de bibliografía académica sobre la cuestión, en particular actas de reuniones bilaterales y multilaterales del Mercado Común del Sur (MERCOSUR) y la Iniciativa para la Infraestructura Regional Suramericana (IIRSA) luego Consejo Suramericano de Planificación (COSIPLAN). En paralelo, los discursos de gobernantes funcionan como soporte en relación a las representaciones que estos tienen sobre el lugar geopolítico de la región, sus perspectivas de desarrollo y las obras de infraestructuras planificadas y ejecutadas.

La segunda sección evalúa la información producida sobre transporte ferroviario, por la IIRSA. Ésta fue creada en la ya mencionada reunión de presidentes de Brasilia del año 2000 y que luego, en 2008, pasara a ser parte de UNASUR como COSIPLAN. Pero además se toman en cuenta instituciones como el Banco Interamericano de Desarrollo (BID), la Corporación Andina de Fomento (CAF) y el Fondo Financiero para el Desarrollo de los Países de la Cuenca del Plata (FONPLATA), en tanto organizaciones internacionales de crédito que desde su fundación han promovido una visión de desarrollo para la región y la infraestructura necesaria para llevarla a cabo. Para esto se tomarán las lecturas acerca del regionalismo, la integración regional y el rol de la infraestructura de transporte.

Es importante remarcar que entre 2008 y 2018 la UNASUR jugó el rol de una institución multilateral de carácter político impulsada por países sudamericanos alineados en su visión político-continental. Tras las derrotas electorales y destituciones de jefes y jefas de Estado de la región que formaban parte del eje "progresista" la UNASUR fue abandonada. En ese contexto, los proyectos dentro de IIRSA/COSIPLAN perdieron el impulso político regional para pasar a ser movilizados por las instituciones crediticias BID, CAF y FONPLATA y por cada Estado.

Entonces planteamos las siguientes preguntas de investigación: ¿cuáles son las consecuencias del uso de los proyectos de ferrocarriles internacionales en tanto potenciadores del desarrollo entendido como crecimiento económico?, ¿cómo se vinculan estos proyectos con un modelo de acumulación basado en la extracción de commodities y que se sustenta en un imaginario de geopolítica de integración regional e inserción internacional?

Estos proyectos serán analizados desde una perspectiva geopolítica (Figura 1). Pero para estos casos, proponemos la categoría de geopolítica de baja intensidad. La baja intensidad está dada por diversas razones. En primer lugar porque, como desarrollamos a lo largo del artículo, estos proyectos avanzan a ritmo lento o nulo. A pesar de eso, es posible explorar los conflictos geopolíticos que se generan durante 
la ejecución de tales proyectos y sus efectos posteriores, tanto a nivel territorial como de la esfera política.

Figura 1. Esquema de actores y perspectivas geopolíticas sobre desarrollo a través del ferrocarril

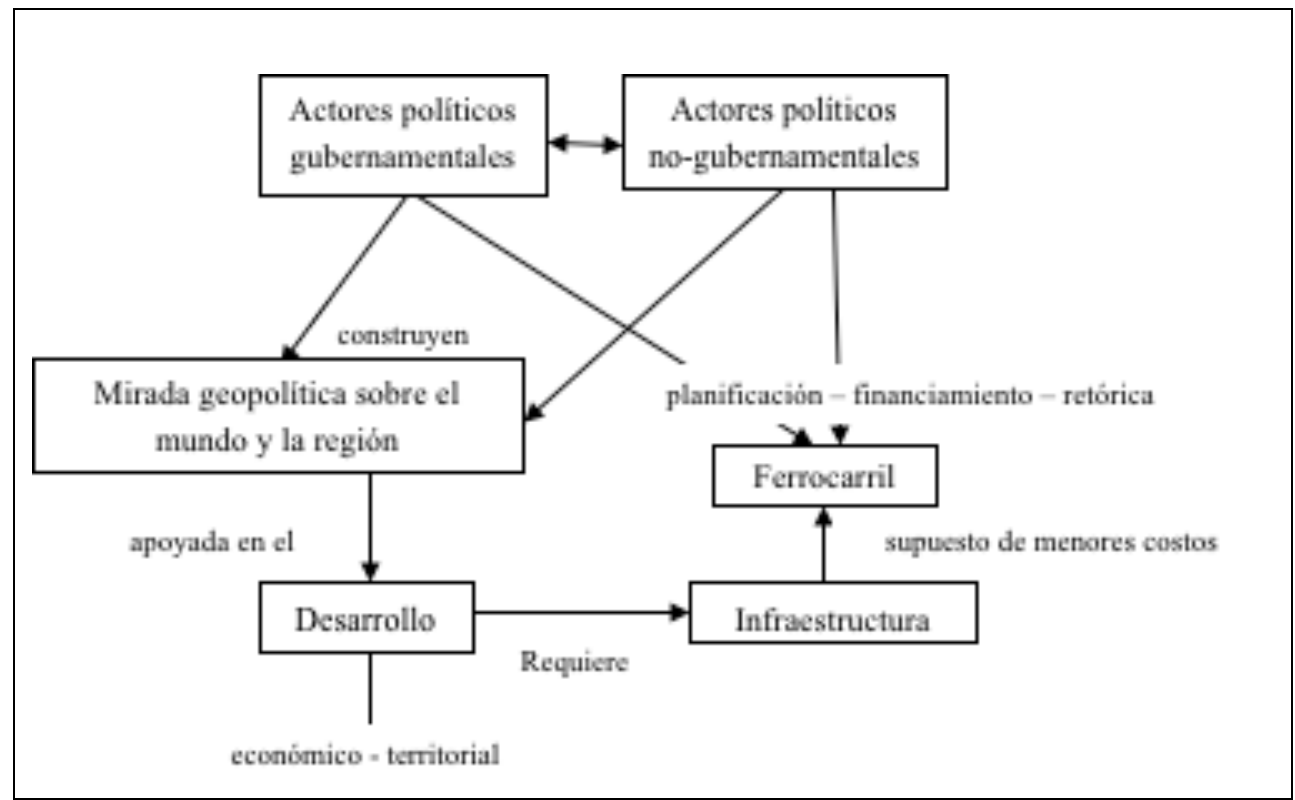

Fuente: elaboración del autor.

Esta geopolítica involucra posicionamientos de diversos y variados actores en relación a perspectivas económicas y las necesidades territoriales para llevarlas adelante. El conflicto, al que denominamos de baja intensidad, parte de una "retórica del ferrocarril-desarrollo". Esta retórica puede documentarse en proyectos políticos variados como los corredores bioceánicos, modelo copiado de Estados Unidos, o la "competencia" entre los modos de transporte.

\section{Marco teórico}

En esta primera sección analizamos diversos trabajos y enfoques sobre geopolítica y ferrocarriles/infraestructuras/desarrollo. Por un lado, retomamos autores clásicos de la geopolítica crítica para dar un marco general de análisis y, por el otro, a quienes trabajaron los casos específicos.

Existen múltiples definiciones y usos para la categoría de geopolítica. Nuestro interés se encuentra en retomar una perspectiva teórico-analítica que permita analizar las dinámicas políticas producto del transporte ferroviario dentro de una lógica de estudios multiescalares. Eso significa no concentrarse únicamente en una escala de análisis, sino con una mirada "vertical" donde los actores políticos atraviesan diversas escalas. Nuestra mirada se aleja de las definiciones cercanas a las relaciones internacionales de geopolítica, donde la corriente realista, sobre todo a partir de la 
década de 1970 y de los textos de Kissinger, logró construir una idea de conflicto expresada en cuestiones militares y de defensa. Retomamos una perspectiva crítica que a lo largo de tres décadas se constituyó como una amalgama teórica nutrida por los postulados de Yves Lacoste en relación a las rivalidades de poder expresadas en los territorios y las representaciones que los actores sociales construyen y, también, como mencionan Preciado y Uc (2010, p.69), una imaginación geopolítica construida por O'Tuathail y Dodds, nutrida de teorías deconstruccionistas y postmodernas retomadas de Foucault y Derrida.

La búsqueda de una mirada que trascienda las relaciones internacionales y la geografía política para estudios geopolíticos desde el Sur es, desde nuestra perspectiva, una cuestión fundamental. Sin duda, en cada país este vínculo se construyó con sus propias especificidades. Sin embargo, a la luz del pensamiento occidental, orientado por la academia norteamericana, la readaptación del uso de algunos conceptos resulta clave en una perspectiva post-colonial. El aporte multiescalar, tanto a la geografía como a las relaciones internacionales, permite estudios centrados en una perspectiva relacional de los actores y sus acciones para controlar e incidir en otros actores y en los territorios y, para nuestro caso, en sus posibilidades de localización como de circulación (Benedetti, 2011).

Milton Santos (1996, p.271) planteaba que lo global era una construcción intelectual que se nutría de lo local y lo transformaba, de forma que, por lo tanto, los capitales y su circulación afectaban a los territorios. Swyngedouw (2004) agrega a esto que la escala local se adapta a la hegemonía global. Entonces, las rivalidades de poder expresadas territorialmente requieren, necesariamente, para ser analizadas, de una perspectiva multiescalar y dinámica.

\subsection{Desarrollo e integración regional}

La CEPAL planteaba en ese entonces que:

La integración regional es un imperativo para acelerar el desarrollo económico de los países latinoamericanos. En este sentido ha sido importante la acción emprendida desde hace años por instituciones regionales e internacionales y por los propios países, en tratados bilaterales y multilaterales. El transporte constituye un instrumento esencial de la integración económica regional, ya que su función económica básica es vencer los obstáculos de la distancia y del territorio y agilizar los desplazamientos de bienes y personas (1972, p.3)

En esa línea, Schteingart y Coatz definen desarrollo como "sinónimo de bienestar generalizado en la población de un país" donde "desarrollo implica una mejora sostenida de la calidad de vida de las sociedades, y ello requiere del incremento de lo que aquí se denominó capacidades tecnológicas" (2015, p.79). En esa línea, esta investigación vincula esa perspectiva del desarrollo con el transporte ferroviario a partir de una mirada geopolítica.

Las cuestiones geopolíticas, así como de desarrollo y su vínculo con el transporte ferroviario y la infraestructura a la luz de los procesos de integración regional, atraviesan una pluralidad de disciplinas y miradas. Nuestro esfuerzo está puesto en retomar algunas miradas singulares que se dieron en los últimos años con el fin de aportar una mirada amplia y sin un sesgo disciplinar específico. Esta búsqueda de 
interdisciplinariedad no resulta habitual. Como antecedentes propios, se pueden mencionar Rascovan $(2016 ; 2017)$. También podemos destacar la producción de Vitte $(2013 ; 2014 ; 2018)$, en tanto analiza las múltiples temáticas involucradas entre la geopolítica, las relaciones internacionales y los procesos de integración regional e IIRSA. Rückert y Pereira Carneiro (2018) también trabajaron acerca del transporte y la integración regional, y agregan el concepto de "oscuridad" para referirse a las regiones periféricas dentro del continente. Esta idea es interesante en tanto ayuda a remarcar los diferentes resultados esperados de las infraestructuras del COSIPLAN. Además, remarcamos los trabajos de Rivarola Puntigliano $(2013 ; 2016)$ quién es uno de los pocos que teoriza sobre geopolítica de la integración regional.

Existen una pluralidad de trabajos acerca de IIRSA, COSIPLAN, Integración Regional y Ferrocarriles Internacionales, sin embargo, el entrecruzamiento disciplinar es en general escaso. Por ejemplo, desde las relaciones internacionales, en un artículo de 2015, Gardini (2015, p.218) propone que "el proceso de la acción retórica se ajusta de manera perfecta a América Latina". Aún más, desde la perspectiva del autor, la retórica escinde los resultados de las políticas de sus discursos y construye una narrativa utilizada por diversos sectores políticos, sean de las élites como a nivel popular. Luego, afirma que "el compromiso con la integración y el regionalismo es una moneda de legitimidad para políticos y que por lo tanto enmarca al discurso y las políticas públicas" (idem.) ${ }^{2}$. Por lo tanto, el foco está centrado en los usos del transporte ferroviario y la movilidad regional como un eslabón más de la cadena retórica utilizada por actores políticos y sociales. Estas necesidades de movilidad se definen en el seno de un conjunto de relaciones sociales y de condiciones territoriales. Es en esta trama compleja donde los sujetos y los grupos sociales definen estrategias de usos de las redes técnicas.

Estas construcciones de redes, sumadas a lo mencionado por Wallerstein acerca de que la infraestructura es un costo pagado por el Estado ya que no son los productores quienes pueden afrontar tales construcciones: "Sí, se trata de bienes públicos, pero el público sólo puede ser especificado hasta un cierto punto" (2006, p.9). Es decir, una infraestructura de transporte, como por ejemplo un ferrocarril, puede ser construida y financiada por un Estado, pero su principal beneficiario ser una empresa privada, en ocasión exenta de impuestos, como fue el caso en Argentina de las empresas inglesas, que no pagaron impuestos por importaciones entre 1907 y 1947. Entonces, el punto pasa a ser ¿a quién beneficia una infraestructura de transporte específica?

Vázquez López (2011) aporta una lectura en relación a la integración económica y el desarrollo en América Latina y el consecuente avance de los procesos de transnacionalización de las economías desde la década de 1960 hasta la de 2000, y llega a la conclusión de que el comercio intrarregional nunca pudo ser visto como opción frente a los mercados globales.

A lo largo de nuestras investigaciones, hemos determinado la existencia de tres grandes períodos geopolíticos en América del Sur. Durante estas etapas, se configuraron relaciones sociales y territoriales entre los Estados, al interior de ellos y con el resto del mundo, sobre la base de perspectivas políticas adoptadas por diversas élites. Las perspectivas geopolíticas adoptadas por los países de la región en términos de relacionamiento comercial y productivo con el resto del mundo oscilaron al compás

Traducción del autor. 
de procesos globales. En términos históricos, por ejemplo, Argentina y Brasil mantuvieron una posición similar desde la segunda mitad del siglo XIX hasta la crisis de los 1930. El objetivo principal era la construcción de un Estado-nación moderno, donde las infraestructuras jugaron un rol fundamental para esto. La construcción de ferrocarriles desde las zonas productivas hasta los puertos marítimos permitió, por un lado, una inserción internacional como productores de materias primas, pero también estructurar sendos territorios nacionales. Esta primera etapa, la denominamos "hacia afuera". Este proceso es relatado por Quagliotti de Belis (1981), quien menciona que desde la formación de los Estados en América del Sur, la división internacional del trabajo los incorporó como actores subdesarrollados gracias a estímulos de crecimiento "hacia afuera".

Rivarola Puntigliano (2010) sostiene que el vínculo entre Argentina, Brasil y Chile en la primera década del siglo XX (ABC) sirvió como preludio para los procesos de integración. Pero, además, el tratado (1915) fue planteado como una contrapartida al modelo de desarrollo promovido por Estados Unidos y su panamericanismo.

La crisis económica desencadenada en 1929 permitió a Argentina y Brasil, sobre todo, profundizar un modelo económico basado en la sustitución de importaciones en una primera etapa y la industria pesada y la tecnología en una segunda. En paralelo, la consolidación de Estados Unidos como potencia global impuso, también, al automóvil y al camión, como modos de transporte por encima del ferrocarril. La expansión del automóvil acompañó un proceso de distribución del ingreso y de crecimiento de los mercados internos, pero también se expandieron las conexiones ferroviarias internacionales. En la segunda postguerra mundial, Argentina y Brasil se embarcaron en modelos de desarrollo económico fundamentalmente industriales. Además, la consolidación de Estados Unidos significó una nueva institucionalización de los procesos de integración regional, empezando por la Organización de los Estados Americanos (OEA) y pasando por otros más regionales.

Sin dudas, la teoría de la dependencia, propuesta por F. H. Cardoso y E. Faletto desde la CEPAL fue fundamental para enmarcar las cosmovisiones sobre el desarrollo en América del Sur durante la década de 1960 en adelante. Los aportes de R. Prebisch ayudaron a consolidar una perspectiva donde se desconfiaba del mercado y el Estado era el motor del desarrollo económico.

La emergencia de políticas económicas neoliberales en la década de 1970, comenzando por Chile y luego implementadas por los diversos gobiernos militares de la región, significó una nueva modificación a la relación entre desarrollo e infraestructuras ferroviarias y territorios. Las escasas líneas ferroviarias internacionales dejaron de funcionar o comenzaron una fase de languidecimiento sostenida.

En paralelo, Manzanal (2010) aporta en relación al largo recorrido del concepto de desarrollo, principalmente a partir de la post Segunda Guerra Mundial, que es necesario desmitificarlo. Esto significa volver cotidianas algunas preguntas que se esconden tras el simplismo ampliamente difundido del uso de desarrollo como "mejora": ¿de qué hablamos cuando hablamos de desarrollo?; ¿a quiénes beneficia este desarrollo?; ¿qué representaciones expresa una determinada infraestructura de transporte?, y ¿puede una misma infraestructura servir a diferentes modos de desarrollo?

En respuesta a estas preguntas, hemos remarcado que, desde la geografía y la economía (Rascovan, 2017), el interés en cuestiones de transporte e infraestructura comenzó a enfocarse en los ferrocarriles internacionales desde comienzos del siglo 
$\mathrm{XX}$, pero que las relaciones internacionales - institucionalizadas a mitad de aquel siglo - nunca lograron tomar estas cuestiones como propias. Dentro de las relaciones internacionales como campo se pueden encontrar los estudios sobre integración regional; Inostroza Fernández y Bolivar Espinoza (2004) explican de manera didáctica el surgimiento de los Ejes de Integración de IIRSA y los corredores bioceánicos, justificando a los ferrocarriles como posibilitadores del desarrollo.

Briceño Ruiz (2013) analiza los procesos de integración regional en Sudamérica y cómo, a partir de los gobiernos "progresistas" de comienzos del siglo XXI, se consolidó una corriente post-liberal dentro del pensamiento regionalista basado en discursos y políticas "neo-nacionalistas" que reclamaban una mejor "gobernanza de la globalización". La creación de la UNASUR, así como también de la Alianza Bolivariana para los Pueblos de Nuestra América - Tratado de Comercio de los Pueblos (ALBA-TCP) son, para este autor, una crítica abierta a un modelo regionalista neoliberal que tuvo gran impacto la década anterior. Sin embargo, no las considera como iniciativas de integración, en tanto los liderazgos presidenciales conducían los mecanismos decisorios.

En esta línea, Sanahuja (2012) planteaba que UNASUR se concentraba en la dimensión política, otorgándole centralidad al Estado y al desarrollo, y que su modelo de cooperación se centraba no en cuestiones vinculadas al comercio, sino a: infraestructura, salud, inclusión social y defensa, entre otros temas. Por su parte, Riggirozzi y Tussie (2012) también argumentaban que UNASUR era una búsqueda política más allá de la integración promovida por Estados Unidos, incorporando una fuerte dimensión normativa en el proceso de integración regional.

Los discursos políticos, al igual que gran parte de la bibliografía sobre integración regional del siglo XXI en América del Sur, tratan la cuestión del desarrollo como algo neurálgico. Álvaro García Linera, vicepresidente de Bolivia, mencionaba:

No se trata de la formación de espacios autárquicos, pues los flujos comerciales mundiales objetivamente articulan las distintas actividades nacionales; pero este mercado mundial y esta economía mundializada desde hace más de 500 años se la hace a partir del espacio nacional como célula. En ese sentido, el mundo capitalista se presenta como una articulación flexible de espacios nacionales capitalistas [...] la narrativa histórica de la economía capitalista tiene dos grandes vertientes; el proteccionismo (con múltiples variantes) y el liberalismo (con múltiples variantes) [...] Pero, aun en los momentos más intensos de proteccionismo, también estará presente una dimensión planetaria de otros flujos económicos, como los flujos tecnológicos, financieros y una división internacional del trabajo (países que producen la materia prima, países que procesan la materia prima, países que hacen productos intermedios y países que generan tecnología de punta) (2017, pp.165-166).

Esta tensión que relata se encuentra plasmada en la infraestructura construida a lo largo de la segunda mitad del siglo XIX. Como veremos luego, es el propio gobierno boliviano, liderado por Morales y el propio García Linera el que se ha manifestado en reiteradas ocasiones a favor de la creación de corredores bioceánicos y de la construcción de infraestructura de transporte en el marco de IIRSA/COSIPLAN.

En Argentina, diversos gobiernos, nacionales y provinciales, se han expresado a favor de los ferrocarriles, en particular los internacionales, como factor de desarrollo. Uno de los casos más intrigantes fue el servicio de pasajeros entre Buenos Aires y 
Montevideo, inaugurado en agosto de 2011 por los gobiernos de Cristina Fernández (Argentina) y José Mujica (Uruguay) ${ }^{3}$. En Argentina, este servicio recorría las vías entonces concesionadas a la empresa brasileña América Latina Logística (ALL), que se encontraban en calamitosas condiciones según la Auditoría General de la Nación (AGN), entre Buenos Aires y la frontera con el Uruguay. El tren motivó una serie de actos políticos y movilizó a la prensa de ambos países, fue cancelado unos meses después de su inauguración ${ }^{4}$.

En la provincia argentina de Mendoza también se propuso, en diversas oportunidades $^{5}$, reconstruir un ferrocarril transandino que vincule a aquella provincia argentina con Chile. También la provincia de Jujuy realizó actividades para proponer la reconstrucción del ferrocarril para la integración ${ }^{6}$. De manera similar, los presidentes de Paraguay y Chile también tuvieron expresiones en relación a la necesidad de nueva infraestructura regional de transporte.

El expresidente de Brasil, Luiz Ignacio da Silva, también tuvo expresiones favorables a los corredores bioceánicos y a la propuesta de infraestructura de IIRSA como modelo de integración regional ${ }^{7}$. Bernal-Meza (2010) remarca que para el gobierno de este presidente era fundamental IIRSA como soporte para el proyecto político a nivel continental que era UNASUR. Esto quedó expuesto cuando, en la XXXVIII Cumbre de Presidentes del MERCOSUR en 2009, todos los presidentes del bloque, sumados a los de Chile y Perú, se expresaron a favor de la construcción de infraestructura y, en particular, de la Iniciativa IIRSA como pilar de aquellos proyectos ${ }^{8}$. Incluso, la primera reunión del Comité Coordinador del COSIPLAN se realizó en Brasil, en 2011, dos años después de la creación del Consejo 9 .

El objetivo de presentar las voces de quienes llevaron las riendas de los poderes ejecutivos durante el período 2000-2015 fue mostrar que la temática de la infraestructura regional, IIRSA y que la integración regional, no fue un tema ajeno a las agendas de los máximos referentes.

\section{Actualidad y proyectos ferroviarios en América del Sur}

Sostenemos que el ferrocarril es un dispositivo socio-tecnológico que conjuga a actores sociales con diferentes intereses y capacidades políticas y que, por lo tanto, los efectos producidos por su existencia no son lineales. En la primera detallamos algunos aspectos claves de la historia ferroviaria en América del Sur. También describimos el estado actual de los ferrocarriles internacionales, las empresas existentes y las líneas en funcionamiento. En la segunda parte, se analizan los proyectos de infraestructura ferroviaria internacional en el marco de IIRSA/COSIPLAN y el lugar de los organismos internacionales de crédito.

\footnotetext{
Ver https://www.perfil.com/noticias/politica/-20110829-0032.phtml

Ver https://es.wikipedia.org/wiki/Tren_de_los_Pueblos_Libres

Ver http://www.abc.com.py/nacionales/acuerdos-entre-cartes-y-pinera-618787.html

Ver https:/www.eltribuno.com/jujuy/nota/2017-6-22-12-39-0-apertura-del-seminario-ferrocarril-para-la-integracion

Ver http://lima.itamaraty.gov.br/es-es/politico.xml

Ver http://archivo.presidencia.gub.uy/_web/noticias/2009/12/2009120818.htm

Ver http://www.itamaraty.gov.br/pt-BR/notas-a-imprensa/2580-conselho-de-infraestrutura-e-planejamentocosiplan-da-unasul-rio-de-janeiro-28-de-abril-de-2011
} 


\subsection{Breve historia de los ferrocarriles internacionales en América del Sur}

En este trabajo nos focalizamos en las movilidades motorizadas y sus requerimientos técnicos. Para el ferrocarril hacen falta vías férreas, para los camiones, automóviles y autobuses hacen falta carreteras, para los aviones hacen falta aeropuertos y radares y para los barcos hacen falta puertos y dragado. En una primera gran etapa de los transportes a nivel continental, que va desde la formación de los Estados nacionales (segunda mitad del siglo XIX) hasta la post Segunda Guerra Mundial, las infraestructuras - tanto su planificación, construcción y propiedad, como el usufructo de los transportes - se produjeron a partir de la interrelación entre los Estados y capitales privados (norteamericanos, ingleses y en menor medida franceses), dependiendo del país pero, en general, centrándose en puertos y ferrocarriles.

Es válido admitir que no existe un sistema ferroviario en América del Sur ${ }^{10}$. A lo largo de la historia han existido y aún continúan existiendo algunas líneas ferroviarias internacionales (Tabla 1). Sin embargo, esto dista de ser un sistema articulado. Las razones son múltiples, incluyendo aspectos técnicos y coyunturas políticas.

Entre los actores sociales más destacados de la región se encuentra la Asociación Latinoamericana de Ferrocarriles (ALAF), fundada en 1964 con el objetivo de potenciar al transporte ferroviario y fortalecer los ejes de integración latinoamericanos. Entre sus metas se encontraban, y se siguen encontrando, homogeneizar las normas técnicas e impulsar proyectos de infraestructura y acceso a puertos.

La CEPAL (1972) también trató el tema ferroviario vinculado a la integración regional, y funcionó como modelo para los informes producidos por los demás organismos internacionales. Se destaca, siempre, una sección de diagnóstico y otra propositiva. Es interesante remarcar que aquel documento ya proponía la idea de corredores, aunque sin denominarlos "bioceánicos", optando por "transcontinental".

Como bien remarcan todos los informes desde la década de 1960 en adelante, una de las principales razones técnicas que imposibilitó una red ferroviaria sudamericana es la pluralidad de trochas utilizadas.

Argentina se destaca como el país con mayores diferencias internas, con tres trochas diferentes en su red interna. Sus líneas de trocha métrica $(1.000 \mathrm{~mm}) \mathrm{se}$ conectan con Chile y Bolivia, mientras que sus líneas de $1.435 \mathrm{~mm}$ o estándar tienen conexiones con Brasil y Uruguay. Sin embargo, la gran mayoría de sus ferrovías son de trocha ancha $(1.676 \mathrm{~mm})$, sin conexiones internacionales pero con presencia en la provincia de Mendoza, lindante con Chile.

En Uruguay los ferrocarriles son de trocha estándar y se conectan con Argentina a través de la Represa Salto Grande, que cruza el Río Uruguay y fue construida entre las décadas de 1970 y 1980.

Brasil, por su lado, mantiene una gran red ferroviaria de trocha angosta y en sus vínculos internacionales con Argentina y Uruguay se utilizan tramos con ambas trochas que hacen posible que los trenes crucen las fronteras.

10 Dada la diversidad de trochas y empresas existentes cuando se construyeron las líneas ferroviarias, el resultado es un entramado de redes inconexas entre sí. Lo más cercano a una red pudo haber sido la empresa Ferrocarriles Argentinos (1952-1992) que nucleó a todas las líneas ferroviarias pero donde cada cual gozaba de una autonomía interna muy grande, además de las diferencias técnicas a nivel de trocha, alimentación y material rodante. 
Tabla 1. Ferrocarriles internacionales en América del Sur

\begin{tabular}{|c|c|c|c|c|c|}
\hline Países & Uso & $\begin{array}{c}\text { Linea } \\
\text { (terminales) }\end{array}$ & $\begin{array}{l}\text { Apertura } \\
\text { (año) }\end{array}$ & $\begin{array}{l}\text { Ancho } \\
\text { Trocha } \\
\text { (en } \mathrm{mm} \text { ) }\end{array}$ & Estado actual \\
\hline $\begin{array}{l}\text { Argentina / } \\
\text { Chile }\end{array}$ & $\mathrm{P}$ & $\begin{array}{l}\text { Buenos Aires - } \\
\text { Santiago } \\
\text { (Transandino) }\end{array}$ & 1910 & 1.000 & Clausurado 1984 \\
\hline $\begin{array}{l}\text { Argentina / } \\
\text { Chile }\end{array}$ & C & Salta - Antofagasta & 1948 & 1.000 & $\begin{array}{l}\text { En funcionamiento } \\
\text { (escaso) }\end{array}$ \\
\hline $\begin{array}{l}\text { Argentina / } \\
\text { Brasil }\end{array}$ & C & $\begin{array}{l}\text { Paso de los Libres - } \\
\text { Uruguayana }\end{array}$ & 1945 & $\begin{array}{l}1.000 / \\
1.435\end{array}$ & $\begin{array}{l}\text { En funcionamiento } \\
\text { (escaso) }\end{array}$ \\
\hline $\begin{array}{l}\text { Argentina / } \\
\text { Uruguay }\end{array}$ & C & Concordia - Salto & 1982 & 1.435 & $\begin{array}{l}\text { En funcionamiento } \\
\text { (muy escaso) }\end{array}$ \\
\hline $\begin{array}{l}\text { Argentina / } \\
\text { Paraguay }\end{array}$ & $P$ & $\begin{array}{l}\text { Posadas - } \\
\text { Encarnación }\end{array}$ & 1990 & 1.435 & $\begin{array}{l}\text { En funcionamiento } \\
\text { (escaso) }\end{array}$ \\
\hline $\begin{array}{l}\text { Argentina / } \\
\text { Bolivia }\end{array}$ & $\mathrm{P}-\mathrm{C}$ & $\begin{array}{l}\text { La Quiaca - } \\
\text { Villazón }\end{array}$ & 1924 & 1.000 & Clausurado \\
\hline $\begin{array}{l}\text { Argentina / } \\
\text { Bolivia }\end{array}$ & $\mathrm{P}-\mathrm{C}$ & $\begin{array}{l}\text { Yacuiba - Santa } \\
\text { Cruz }\end{array}$ & $\begin{array}{c}1944 / \\
1957\end{array}$ & 1.000 & Clausurado en 1990 \\
\hline $\begin{array}{l}\text { Brasil / } \\
\text { Uruguay }\end{array}$ & $\mathrm{C}$ & $\begin{array}{l}\text { Santana do } \\
\text { Livramento - } \\
\text { Rivera }\end{array}$ & 1912 & 1.435 & $\begin{array}{l}\text { Sin funcionamiento } \\
\text { desde fines } 1990\end{array}$ \\
\hline $\begin{array}{l}\text { Brasil / } \\
\text { Uruguay }\end{array}$ & C & $\begin{array}{l}\text { Jaguarao - Río } \\
\text { Branco }\end{array}$ & 1932 & $\begin{array}{l}1.000 / \\
1.435\end{array}$ & $\begin{array}{l}\text { Sin funcionamiento } \\
\text { desde } 1980\end{array}$ \\
\hline $\begin{array}{l}\text { Brasil / } \\
\text { Uruguay }\end{array}$ & C & $\begin{array}{l}\text { Barra do Quaraí - } \\
\text { Cuareim }\end{array}$ & 1908 & 1.435 & $\begin{array}{l}\text { Sin funcionamiento } \\
\text { desde } 1965\end{array}$ \\
\hline $\begin{array}{l}\text { Brasil / } \\
\text { Bolivia }\end{array}$ & C & $\begin{array}{l}\text { Corumbá - Santa } \\
\text { Cruz }\end{array}$ & 1955 & 1.000 & $\begin{array}{l}\text { En funcionamiento } \\
\text { (con intermitencias) }\end{array}$ \\
\hline $\begin{array}{l}\text { Chile / } \\
\text { Perú }\end{array}$ & $\mathrm{P}$ & Arica - Tacna & $\begin{array}{c}1850 / \\
1929\end{array}$ & 1.435 & En funcionamiento \\
\hline $\begin{array}{l}\text { Bolivia / } \\
\text { Chile }\end{array}$ & C & La Paz - Arica & 1913 & 1.000 & Cerrado \\
\hline $\begin{array}{l}\text { Bolivia / } \\
\text { Chile }\end{array}$ & C & $\begin{array}{l}\text { La Paz - } \\
\text { Antofagasta }\end{array}$ & 1917 & 1.000 & En funcionamiento \\
\hline
\end{tabular}

Fuente: Benedetti (2005), Rascovan (2014), Rascovan (2017),

http://www.iirsa.org/admin_iirsa_web/Uploads/Documents/Anexo3_InsumosParaEstrategia_Integraci $\% \mathrm{C} 3 \% \mathrm{~B} 3 \mathrm{n}$ FerroviariaSuram\%C3\%A $\%$ rica.pdf ${ }^{11}$.

11 Resulta interesante que el informe encargado por IIRSA a una consultora privada cuenta con errores como la mención de un ferrocarril entre Bolivia y Perú, al punto que en el mismo sitio de IIRSA aparece el proyecto de unión entre ambos países AND54; ver http://www.iirsa.org/proyectos/detalle_proyecto.aspx?h=843 . Además, el mencionado trabajo cuenta con informaciones desactualizadas sobre el estado actual del funcionamiento. 
No existe una única perspectiva acerca de las motivaciones para la construcción de ferrocarriles internacionales. En el caso de Chile con Bolivia la línea ferroviaria internacional se estableció en el artículo 3 del Tratado de Paz y Amistad de 1904 tras la Guerra del Pacífico (1879-1884) ${ }^{12}$. La infraestructura, en este caso, parece haber sido utilizada para compensar por los territorios que Chile conquistó en el conflicto bélico y para evitar que las tensiones volvieran a escalar, ofreciendo a Bolivia una salida al mar a pesar de la derrota. En paralelo, la explotación de salitre y otros minerales por diversas empresas inglesas (entre las cuales se destacan Anthony Gibbs \& Sons; Williamson \& Co.; Duncan Fox y Buchanan Jones \& Co.) también formó parte de un modelo económico característico de la época (González Pizarro, Lufin Varas y Galeno Ibaceta, 2014).

En el caso argentino esto fue diferente. La red ferroviaria creció hacia la zona productiva pampeana, vinculándolas con los principales puertos: Rosario, Bahía Blanca y, por supuesto, Buenos Aires. Esto fue similar en el caso de Uruguay:

El tren tuvo una importancia vital en la reconfiguración del comercio mundial. La estrategia de extensión de las ferrovías en los países de América Latina y de otras regiones del mundo fue concebida como una forma de transportar materias primas para la exportación, de acuerdo al objetivo ideado por las potencias de la época para poder acceder a materiales que serían industrializados y comercializados por las empresas de las economías más avanzadas. Esa función de ferrocarriles muy evidente en el diseño de la red uruguaya extendida por los inversores británicos, donde todas las líneas convergen en el puerto de Montevideo (Setelich, 2013, p.214).

En el caso de Brasil, aunque la lógica fue la misma, se construyeron dos polos en paralelo: entre la ciudad de San Pablo y el interior del Estado homónimo y entre la ciudad de Río de Janeiro y el interior del Estado del mismo nombre. El objetivo era claro: poder exportar café y caucho. Es ineludible la mención a los capitales extranjeros. Las principales empresas ferroviarias de la época eran inversiones británicas $\mathrm{y}$, en menor medida, francesas, belgas y norteamericanas, muchas veces en coalición con capitales locales. En Brasil la empresa The São Paulo Railway Company (SPRC) de $139 \mathrm{~km}$ fue construida por capitales británicos para cubrir el trayecto entre el Puerto de Santos con la zona cafetera de Jundiaí.

Similar es el caso de Uruguay, donde en 1866 se creó la empresa Ferrocarril Central del Uruguay (FCU) que se financió a partir de un préstamo de la firma inglesa Baring Brothers. La situación es relativamente similar en Paraguay. Tras la desastrosa guerra que enfrentó a Paraguay con Argentina, Brasil y Uruguay (1865-1870), en 1871 el nuevo gobierno privatizó la línea entre Asunción y Villa Rica sólo para pagar las deudas con la Tesorería del Imperio de Brasil. En ese mismo año se aprobó un empréstito de 1.000 .000 de libras esterlinas a través de los banqueros Robinson \& Fleming Co. Un año después Paraguay contrajo otro préstamo, esta vez de 2.000.000 de libras esterlinas. En un comienzo, la empresa que se hizo cargo de la línea Asunción - Villa Rica incluía capitales paraguayos. Sin embargo, en 1878 fue vendida a la Rohe y Cía., de Nueva York.

12 Ver https://es.wikisource.org/wiki/Tratado_de_Paz_y_Amistad_entre_Chile_y_Bolivia 
Además de los aspectos técnicos se encuentran los políticos. Cada conexión internacional representaba una sumatoria de intereses económicos y políticos. El ferrocarril transandino implicó intereses de comerciantes de la región cuyana ${ }^{13}$ y también una perspectiva en política exterior entre Argentina y Chile (Lacoste, 2013). De modo similar, la construcción del Puente Internacional Agustín P. Justo - Getulio Vargas fue empujada por casi dos décadas por comerciantes de Paso de los Libres y Uruguayana, pero sólo se concretizó cuando los gobiernos de Argentina y Brasil consideraron que no afectaba sus intereses en defensa nacional. En cambio, la conexión entre Argentina y Uruguay y entre Argentina y Paraguay responden a un contexto de integración regional. El primero estaba apoyado en las necesidades energéticas y los vínculos entre gobiernos militares. El segundo, se valía del contexto previo a la emergencia del MERCOSUR como institucionalización del vínculo regional.

En casi todos los países, el modelo de monopolio estatal duró hasta la década de 1990, cuando se permitió la entrada a capitales privados. En el caso de las líneas internacionales, el ferrocarril transandino ya estaba suspendido desde la década de 1980. La red de trocha estándar, en Argentina, que comunica con Uruguay, Brasil y Paraguay se concesionó en 1993 como Ferrocarril de la Mesopotamia, para ser luego adquirido en 1999 por la empresa brasileña América Latina Logística, que también adquirió la concesión de la red ferroviaria federal en Brasil para los estados de Paraná, Santa Catarina y Rio Grande do Sul. Este caso fue histórico, ya que es fue la única vez en la historia que una empresa fue concesionaria en dos países y buscó llegar a ambos océanos.

Los ferrocarriles internacionales de Uruguay se encuentran desactivados y, solamente, Paraguay mantiene un servicio de pasajeros con Argentina (Encarnación Posadas). Este servicio funciona con intermitencias desde el año 2016.

Quizá el caso más interesante sea el de Bolivia que cuenta con cinco conexiones internacionales, de las cuales dos se encuentran en funcionamiento, una con Chile y otra con Brasil, aunque esta última con problemas debido a modificaciones con la empresa concesionaria brasilera Rumo que se hizo cargo de la malha oeste tras su fusión con la antigua operadora América Latina Logística. La pérdida de la salida al mar tras la Guerra del Pacífico a fines del siglo XIX es vista, hoy, como una de las grandes problemáticas económicas desde el gobierno de Evo Morales y, por esa razón, ha impulsado diversos reclamos en cortes internacionales para obtener una porción de costa. En esa línea se inscribe la búsqueda de fortalecer los corredores bioceánicos y retomar las conexiones ferroviarias con Argentina y Brasil y conectarse con Perú ${ }^{14}$.

El informe de Ian Thomson (1995) para el BID presenta un escenario de optimismo en tanto las estadísticas de fines de la década de 1990 mostraban un repunte en algunos casos (Argentina y Chile sobre todo) y una continuidad en el aumento del tráfico ferroviario entre Brasil y Bolivia. A su vez, muestra como en 1986, los ferrocarriles internacionales representaban un porcentaje muy elevado sobre el total de las cargas ferroviarias para las únicos países del continente sin salida directa a los océanos, Bolivia $87,6 \%$ y Paraguay $61,8 \%$.

13 Región de Argentina que comprende las provincias de Mendoza, San Juan y San Luis. Las primeras dos se encuentran en la frontera con Chile sobre la Cordillera de los Andes.

14 Ver http://www.semagro.ms.gov.br/brasil-e-bolivia-firmam-acordo-para-viabilizacao-da-ferroviatransamericana/ 


\subsection{IIRSA/COSIPLAN y el futuro del ferrocarril}

La creación de organismos como la OEA y del BID fue determinante para poner en juego una nueva necesidad de la infraestructura, orientada al mejoramiento de la rentabilidad exportadora de los países y al abaratamiento de costos.

La reunión de Jefes de Estado del año 2000 en Brasilia produjo un documento, la "Declaración de Brasilia" que concretizó debates que llevaban más de 40 años en la región. La cooperación bilateral entre Argentina y Brasil en cuestiones de transporte, por ejemplo, había comenzado en la década de 1950 en la Comisión Especializada Brasileño Argentina de Cooperación (CEBAC), un foro de diplomacia que se expandió a otras áreas gubernamentales. Durante la década de 1960 y 1970 hubo una serie de reuniones con relativa frecuencia donde las temáticas del transporte eran discutidas por diversos actores estatales (Rascovan, 2014)

Con el retorno a la democracia en la década de 1980 estos foros bilaterales se convirtieron en multilaterales, también amparados en la creación de la Asociación Latinoamericana para la Integración (ALADI). En 1991 se firma el Tratado de Asunción entre Argentina, Brasil, Paraguay y Uruguay, el cual crea el MERCOSUR con el objetivo primordial de facilitar el comercio internacional entre estos países y, sobre todo, avanzar en aranceles comunes y políticas comerciales entre el bloque y el resto del mundo. El Protocolo de Ouro Preto (1994) institucionalizó el MERCOSUR, dando lugar a diversos Subgrupos de Trabajo temáticos. El SGT5 se encargaría de Transporte e Infraestructura, recogiendo la experiencia de trabajo de casi cuatro décadas.

Sin embargo, la creación de IIRSA en el año 2000 significó un quiebre mayúsculo para estas temáticas. La resolución 89/00 del Grupo Mercado Común (GMC), el órgano ejecutivo del MERCOSUR, creó la Reunión Especializada de Infraestructura de la Integración ${ }^{15}$, y, en paralelo, la decisión 59/00 del Consejo del Mercado Común (CMC), el órgano decisorio superior del MERCOSUR, firmada el 14 de diciembre de aquel año, cambió el nombre del SGT 5 (Transporte e Infraestructura) por Transporte. La resolución 89/00 hace referencia a "la prioridad conferida al desarrollo de una infraestructura común en el continente, por los Presidentes de la República de los Países de América del Sur, en la 'Declaración de Brasilia' del $1^{\circ}$ de septiembre del 2000”. Este pasaje de las temáticas de la infraestructura regional del ámbito del MERCOSUR a IIRSA, era también un planteo político, donde algunas cuestiones relativas a la atenuación de las asimetrías y la facilitación de normativas de frontera perdieron lugar en la agenda de trabajo para ser reemplazadas por un pensamiento arraigado en las tradiciones de organismos internacionales del crédito como el BID.

La IIRSA funcionó durante 9 años como reservorio de experiencias pasadas en relación a la planificación la infraestructura regional, pero también profundizó en categorizar los territorios de acuerdo a los intereses expresados por los países. La iniciativa entonces contenía Agendas Prioritarias de Inversión (API), retomaba la idea de corredores bioceánicos (interconexión entre los océanos Atlántico y Pacífico) y dividía el continente en Ejes de Inversión y Desarrollo (EIDs). Dentro de cada EID se encontraban diferentes grupos y dentro de cada uno de estos los proyectos que a su vez tenían cuatro categorías, perfil, pre-ejecución, ejecución y concluidos.

15 Es fundamental remarcar que en el sitio web del Mercosur no existe información disponible acerca de la REII más allá de las decisiones del CMC y del GMC sobre su creación y las actas de la primera reunión en el 2001. 
En 2009 IIRSA pasó a formar parte de la UNASUR. La Tercera Reunión del Consejo de Jefas y Jefes de Estado de UNASUR realizada en la ciudad de Quito creó el COSIPLAN. El Estatuto y el Reglamento del Consejo fueron aprobados por los Ministros en la Primera Reunión Ordinaria y ratificados posteriormente por la Cuarta Reunión del Consejo de Jefas y Jefes de Estado, en la misma se remarcó que: "El COSIPLAN es la instancia de discusión política y estratégica, a través de la consulta, evaluación, cooperación, planificación y coordinación de esfuerzos y articulación de programas y proyectos para implementar la integración de la infraestructura regional de los países miembros de la Unión de Naciones Suramericanas (UNASUR)" $" 16$.

El Grupo de Trabajo sobre Integración Ferroviaria (GTIF) había sido creado en 2001 con el objetivo de potenciar la integración regional y la infraestructura ferroviaria regional. En el acuerdo que enmarca su creación se destaca la idea de complementariedad de políticas y proyectos que "impulsen el desarrollo económico y social". Esta definición no dista mucha de aquellas expresadas en las reuniones de la década del 1960, sin embargo, es el contexto social y productivo el que se modificó radicalmente.

La idea del GT era retomar la experiencia de los trabajos que ya se venían realizando sobre el Corredor Ferroviario Bioceánico Paranaguá-Antofagasta que formaba parte de la $\mathrm{API}^{17}$. En una medida que buscó facilitar el trabajo, el GTIF se dividió, tras la reunión de 2012, en dos Subgrupos de Trabajo SGT: Sub-Grupo del Corredor Ferroviario Bioceánico Paranaguá-Antofagasta (Argentina-Brasil-Chile-Paraguay) que comenzó a funcionar en 2014 y, Sub-Grupo del Corredor Ferroviario Bioceánico Central (Bolivia-Brasil-Perú) desde 2015.

Estos subgrupos están encargados de trabajar en forma específica sobre los avances de los proyectos prioritarios. La Cartera de Proyectos del COSIPLAN cuenta con 67 proyectos ferroviarios por una inversión estimada de más de US\$ 47.000 millones. En su informe de 2017, IIRSA/COSIPLAN contaba con 589 proyectos y una inversión estimada de US\$ 173.646 millones (Figuras 2 y 3 ).

A pesar de la elocuencia expresada por los números, consideramos necesario indagar en cuáles son estos proyectos específicos y si son viables como tales. Uno de los proyectos que aparece dentro de la Agenda Prioritaria de Inversión es la Rehabilitación del ferrocarril Jujuy - La Quiaca en Argentina, denominado CAP 11. Esta línea ferroviaria permitiría volver a conectar la línea Belgrano Cargas (Argentina) con el Ferrocarril Oriental (Bolivia). Entre 2017 y 2018 se avanzó en la firma de tratados entre Argentina y Bolivia y la construcción de $4 \mathrm{~km}$ de vías, con el objetivo de llegar a la frontera entre ambos países para $2023^{18}$. Este proyecto se encuentra movilizado, principalmente, por el gobernador de la provincia argentina de Jujuy, con el "desarrollo" como principal objetivo de las inversiones ${ }^{19}$. Sin embargo, este proyecto no cuenta con la información suficiente acerca de cuánta carga se trasladará y cuáles serán los servicios ofertados.

\footnotetext{
16 Ver IIRSA/COSIPLAN http://iirsa.org/Page/Detail?menultemid=119

17 Ver http://www.iirsa.org/admin_iirsa_web/Uploads/Documents/rc_brasilia11_acuerdo3_integracion_ferroviaria.pdf

18 Ver http://prensa.jujuy.gob.ar/2017/07/11/jujuy-afianza-la-integracion-fronteriza/

19 Ver http://prensa.jujuy.gob.ar/2018/02/22/historico-inicio-la-instalacion-de-rieles-del-tren-jujeno/
} 
Figura 2. Proyectos IIRSA/COSIPLAN (2017)

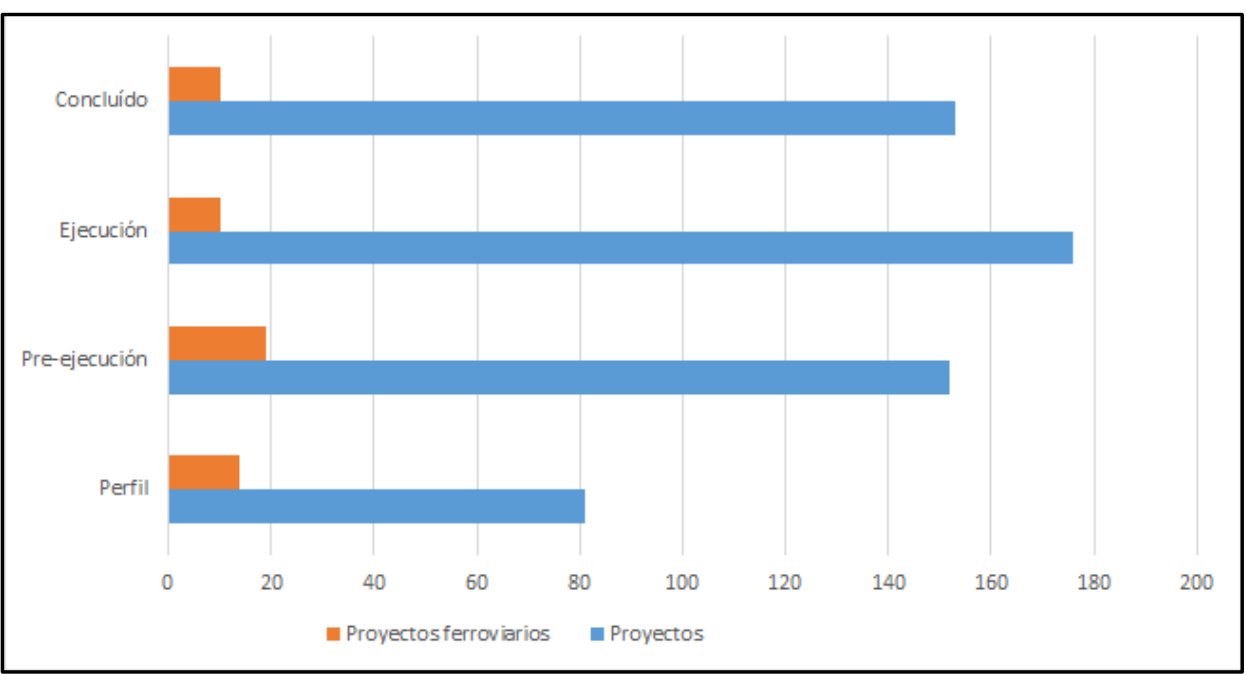

Fuente: Elaboración del autor a partir de

http://www.iirsa.org/admin_iirsa_web/Uploads/Documents/CARTERA_DIGITAL.pdf

Otro ejemplo de los estudios realizados sobre ferrocarriles en América del Sur, es el que en 2013 encargó el Ministerio de Obras Publicas y Comunicaciones de Paraguay. El informe, realizado por la Agencia Coreana de Cooperación Internacional $^{20}$, además de tener errores de ortografía, presenta a la construcción de la ferrovia con los países limítrofes en el marco de una "Ferrovia Bioceánica" a la dirección Chile y Brasil, pasando por Argentina, como la mejor opción para el desarrollo del comercio.

Figura 3. Inversiones de IIRSA/COSIPLAN en dólares norteamericanos (2017)

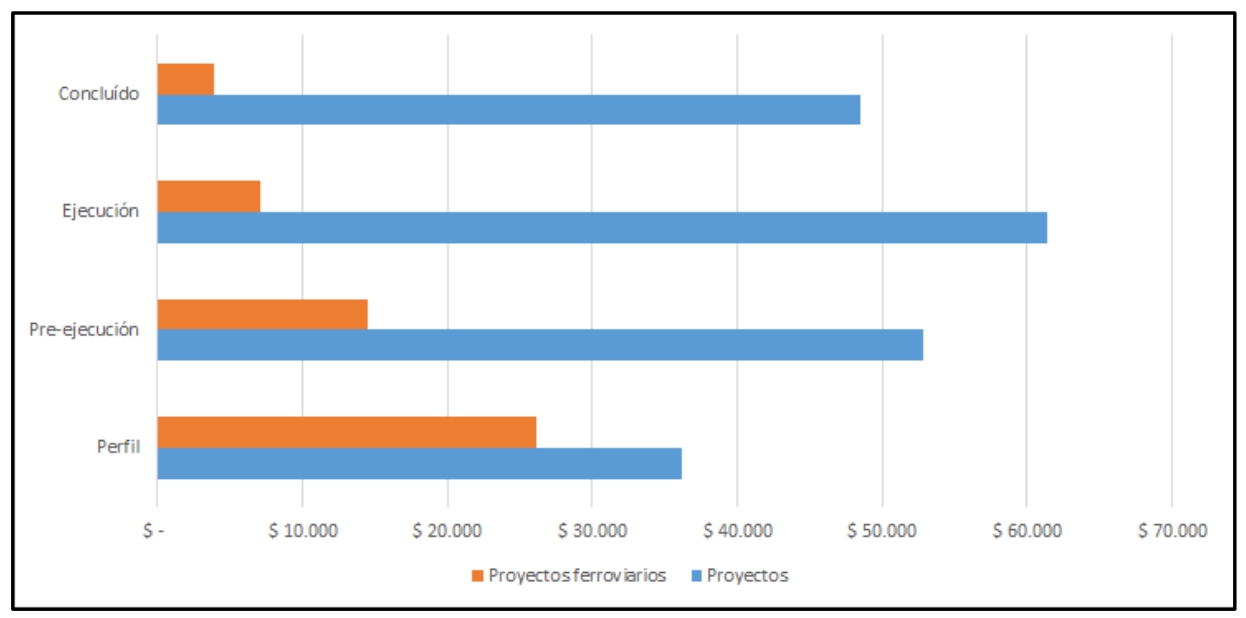

Fuente: Elaboración del autor a partir de

http://www.iirsa.org/admin_iirsa_web/Uploads/Documents/CARTERA_DIGITAL.pdf

20 Ver http://www.iirsa.org/admin_iirsa_web/Uploads/Documents/if_santiago13_anexo9_paraguay.pdf 
En 2017, IIRSA/COSIPLAN publicó un informe denominado "Insumos para Elaborar una Estrategia que Facilite la Integración Ferroviaria de Suramérica". Su importancia radica en que comenzó a centralizar información que durante años se encontró desperdigada. Entre los aportes sustanciales se encuentra bien explayada la prioridad de ciertos corredores por sobre otros, las dificultades históricas y presentes del transporte ferroviario - sobre todo el internacional $-\mathrm{y}$, remarca que los planes de desarrollo a mediano y largo plazo para la región involucran la producción agrícola, agroindustrial y de alimentos, forestal, minera, combustibles y petróleo y su exportación a través de los puertos de ultramar. Por lo tanto, la reducción de los costos logísticos para estas actividades es la oportunidad que, según el documento, el ferrocarril debería aprovechar para expandirse.

El informe, encargado a una consultora privada, resume algunos puntos que se repiten a lo largo de los años. Entre ellos, destacamos:

- "En tres cuartos de siglo la longitud de líneas férreas en Sur América disminuyó a casi la mitad."

- "El rol de los ferrocarriles en la integración económica entre las economías de los estados suramericanos, hasta ahora se ha frustrado."

- "Pocas conexiones ferroviarias siguen hoy activas con un rol significativo."

- "En algunos países de la región los ferrocarriles están casi o totalmente inactivos.”(IIRSA/COSIPLAN, 2017).

Este diagnóstico no difiere mucho de los realizados a principios del siglo XXI. Un punto interesante reside en la idea de corredores y en cuáles deberían ser los priorizados. En este informe se critica, por primera vez, la idea de corredores:

- "No es realista concebir los corredores entre puertos del Atlántico y del Pacífico como 'puentes terrestres'."

- "Las distancias marítimas al Lejano Oriente no difieren mucho desde Valparaíso o Buenos Aires, ni desde Santos o Arica."

- "El paso de los Andes para los ferrocarriles es extremadamente costoso, por las rampas."

- “Los corredores 'bioceánicos' sólo darán una opción para las producciones masivas radicadas en los altiplanos boliviano o argentino o en áreas recostadas sobre el este de la cordillera." (IIRSA/COSIPLAN, 2017).

Esta crítica interna muestra un cambio frente a una posición existente desde hace décadas. Es la primera vez que un organismo multilateral, en temas de transporte, presenta una perspectiva opuesta a los corredores bioceánicos.

Además, el documento reúne las definiciones que habían sido producidas por otras organizaciones como la ALAF, que desde la década de 1960 propone la construcción de ferrocarriles como facilitadores para la exportación y, sobre todo, como mejoradores de productividad ${ }^{21}$. Entre los objetivos del informe se encuentra simplificar la información en relación a los ferrocarriles existentes y los futuros proyectos (Tabla 2).

21 Ver http://www.alaf.int.ar/?pag=revista\&id=142 
Tabla 2. Estado de situación de los corredores y líneas ferroviarias internacionales en América del Sur

\begin{tabular}{|c|c|c|c|c|}
\hline Corredor & Terminología & $\begin{array}{l}\text { Paises } \\
\text { involucrados }\end{array}$ & Zonas prioritarias & Aspectos técnicos \\
\hline $\begin{array}{l}\text { Bioceánico } \\
\text { Central }\end{array}$ & CFBC & $\begin{array}{l}\text { Brasil - } \\
\text { Bolivia - } \\
\text { Chile - } \\
\text { Perú }\end{array}$ & $\begin{array}{l}\text { Área de San Pablo } \\
\text { y Puerto de Santos } \\
\text { (Bra) } \\
\text { Puertos de } \\
\text { Antofagasta y/o } \\
\text { Arica(Chi) o } \\
\text { Matarani (Per) }\end{array}$ & $\begin{array}{l}1.000 \mathrm{~mm} \text {, salvo } \\
\text { tramo en Perú } \\
1.435 \mathrm{~mm}\end{array}$ \\
\hline $\begin{array}{l}\text { Bioceánico } \\
\text { Paranagua } \\
\text { Antofagasta }\end{array}$ & CFBPA & $\begin{array}{l}\text { Brasil - } \\
\text { Paraguay - } \\
\text { Argentina - } \\
\text { Chile }\end{array}$ & $\begin{array}{l}\text { Puerto de } \\
\text { Paranaguá (Bra) } \\
\text { Puertos de } \\
\text { Antofagasta y } \\
\text { Mejillones (Chi) }\end{array}$ & $\begin{array}{l}\text { Tramos nuevos a } \\
\text { construir en } \\
\text { territorio brasileño } \\
\text { y paraguayo. En el } \\
\text { tramo paraguayo } \\
\text { se establecería una } \\
\text { trocha de } 1.000 \\
\text { mm, diferente a la } \\
\text { de las líneas } \\
\text { preexistentes (hoy } \\
\text { inactivas). }\end{array}$ \\
\hline $\begin{array}{l}\text { Argentina - } \\
\text { Uruguay }\end{array}$ & IFPAU & $\begin{array}{l}\text { Paraguay - } \\
\text { Argentina - } \\
\text { Uruguay }\end{array}$ & $\begin{array}{l}\text { Paraguay - Buenos } \\
\text { Aires (Arg) y } \\
\text { Montevideo (Uru) }\end{array}$ & $\begin{array}{l}1.435 \mathrm{~mm} \text { Está en } \\
\text { estado calamitoso. }\end{array}$ \\
\hline $\begin{array}{l}\text { Brasil - } \\
\text { Uruguay - } \\
\text { Argentina }\end{array}$ & IFBUA & $\begin{array}{l}\text { Brasil - } \\
\text { Uruguay - } \\
\text { Argentina }\end{array}$ & $\begin{array}{l}\text { San Pablo y } \\
\text { Estados del sur } \\
\text { (Bra), Buenos } \\
\text { Aires (Arg) y } \\
\text { Montevideo (Uru). }\end{array}$ & $\begin{array}{l}1.000 \mathrm{~mm} \text { en } \\
\text { Brasil y } 1.435 \mathrm{~mm} \\
\text { en Argentina y } \\
\text { Uruguay. }\end{array}$ \\
\hline $\begin{array}{l}\text { Brasil - } \\
\text { Perú }\end{array}$ & CFBBP & $\begin{array}{l}\text { Brasil - } \\
\text { Perú }\end{array}$ & $\begin{array}{l}\text { Puertos brasileños } \\
\text { del Atlántico y } \\
\text { peruanos del } \\
\text { Pacífico brasileño } \\
\text { (de Ilhéus, que se } \\
\text { encuentra a casi la } \\
\text { misma latitud que } \\
\text { Lima, y el puerto } \\
\text { peruano de } \\
\text { Bayóvar) }\end{array}$ & \\
\hline $\begin{array}{l}\text { Trasandino } \\
\text { Central }\end{array}$ & CFTC & $\begin{array}{l}\text { Argentina - } \\
\text { Chile }\end{array}$ & $\begin{array}{l}\text { Buenos Aires } \\
\text { (Arg) - Valparaíso } \\
\text { (Chi). }\end{array}$ & $\begin{array}{l}1.676 \mathrm{~mm} \text {. La vía } \\
\text { está destruida y } \\
\text { hay necesidad de } \\
\text { un túnel en los } \\
\text { Andes }\end{array}$ \\
\hline $\begin{array}{l}\text { Bolivia - } \\
\text { Argentina }\end{array}$ & CFBA & $\begin{array}{l}\text { Bolivia - } \\
\text { Argentina }\end{array}$ & $\begin{array}{l}\text { Bolivia - Río de la } \\
\text { Plata }\end{array}$ & $1.000 \mathrm{~mm}$ \\
\hline
\end{tabular}

Fuente: Elaboración personal. 
Los 7 corredores ferroviarios que IIRSA/COSIPLAN rehabilitaría y construiría están localizados, en su mayoría, donde la infraestructura ya se encuentra instalada, aunque, en casi todos los casos, con condiciones muy malas para la operación o donde las interconexiones faltantes no son extensas.

Sin embargo, más allá de los corredores priorizados, los resultados de los proyectos ferroviarios de IIRSA/COSIPLAN han sido escasos. Hasta 2018 sólo se habían concluido estaciones y centros de transferencia en Brasil, la mejora de la línea Antofatasta - Salta en territorio chileno y algunos kilómetros de vías en Argentina en la antigua línea de Buenos Aires al Pacífico, renombrada General San Martín durante el primer gobierno peronista. Al mismo tiempo, podemos observar como la gran parte de los proyectos estudiados se encuentran en Argentina, mientras que aquellos en proceso de ejecución se concentraban en Uruguay. Estos proyectos ferroviarios de IIRSA/COSIPLAN priorizaron secciones de ferrocarriles nacionales con potencial de aumentar la carga de mercaderías para la exportación. En la Figura 4 observamos como los proyectos ferroviarios de Argentina tienen como principal destino los puertos ubicados en el Río Paraná y Paraguay, de igual forma en Uruguay los puertos sobre el Río de la Plata y el Río Uruguay y en el caso de Chile sobre el océano Pacífico.

Figura 4. Mapa de los proyectos ferroviarios de IIRSA/COSIPLAN

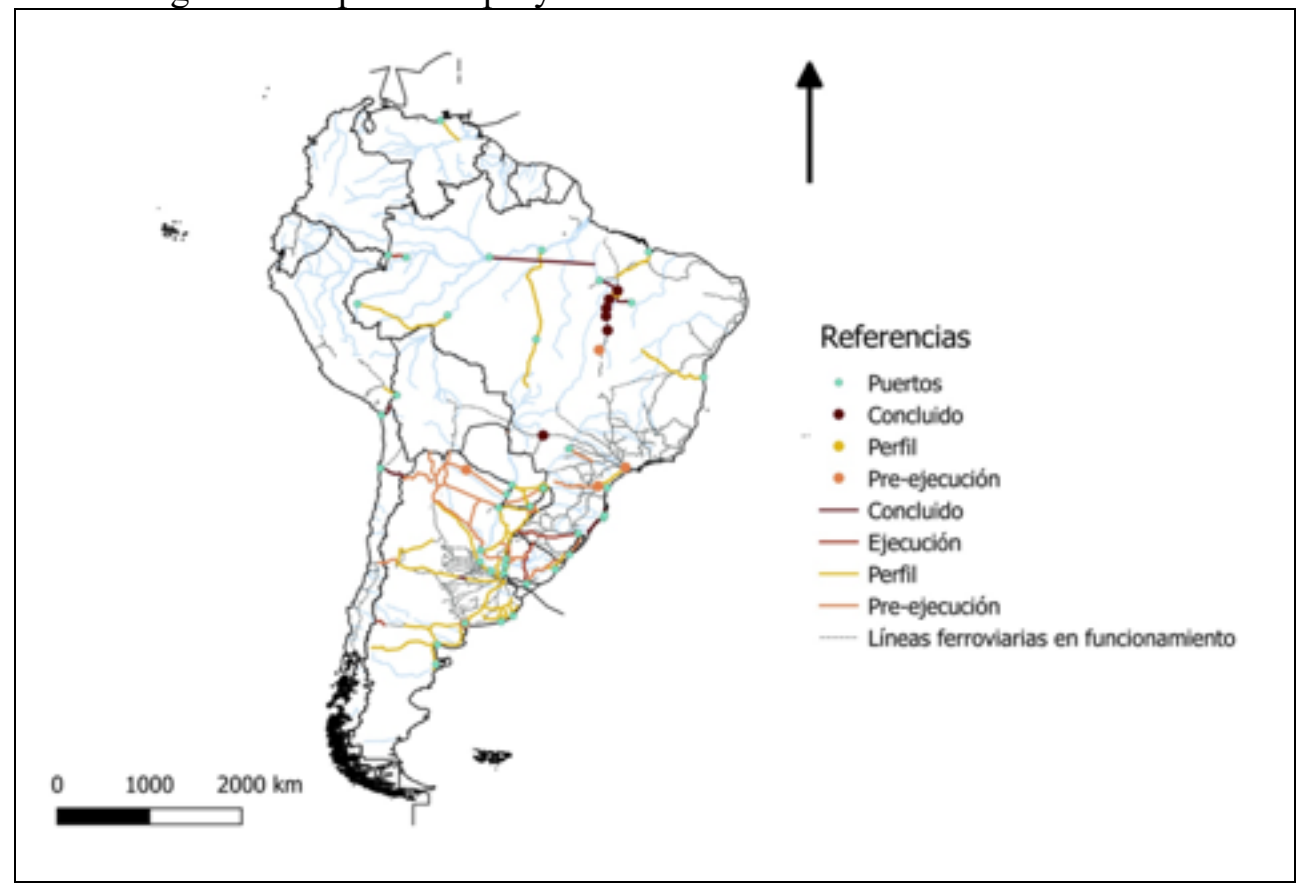

Fuente: Elaboración personal sobre la base del www.cosiplan.org

La realidad de las inversiones con sus diferencias entre lo planeado en cada país y ejecutado muestra un escenario de proyección ferroviaria donde los países continúan apostando a este modo de transporte. Sin embargo, los resultados operativos son irregulares a lo largo de la región. En Argentina con un mercado dividido entre 
una gran empresa pública (Belgrano Cargas y Logística S.E.) y tres prestadores privados (Ferroexpreso Pampeano, Ferrosur Roca y Nuevo Central Argentino), la concentración de cargas en 2017 se dio en dos rubros, granos $41 \%$ y minerales y materiales de la construcción $27 \%$. El total de cargas transportadas ese año fue de 18.809.467 Tn, cantidad similar al año $1998^{22}$.

En el caso de Brasil, la red está conformada por siete empresas privadas las cuales forman parte de grupos industriales o logísticos. La más pequeña es la Ferrovia Teresa Cristina con $164 \mathrm{~km}$ en el estado de Santa Catarina mientras que la empresa Rumo suma más de $14.000 \mathrm{~km}$ en las zonas centro y sur del país. A ésta se le suman la Ferrovía Transnordestina Logística, MRS Logística, Vale, VLI y FERROESTE. En 2017 se transportaron 538,8 millones de Tn, de las cuales 416 corresponden al sector minero.

En Uruguay, la única empresa de carga SLF, está conformada por dos agencias estatales. En el año 2017 transportó 519.000 Tn, la cifra más baja desde $2003^{23}$.

Por su parte Chile cuenta con seis empresas privadas, Ferrocarril de Antofagasta (FCAB), Empresa de Transporte Ferroviario S.A. (FERRONOR), Compañía Minera del Pacífico S.A. (CMP), Sociedad Química y Minera de Chile (SQM) y Ferrocarriles del Pacífico S.A. (FEPASA) y Transporte Ferroviario Andrés Pirazzoli S.A. (TRANSAP). En 2018 estas empresas transportaron 25.662.752 Tn, de las cuales el 69,9\% fueron cargas a granel sólido, además, 22.590.000 tuvieron como destino final o inicial un puerto ${ }^{24}$.

A su vez, Bolivia cuenta con dos empresas, Ferroviaria Andina S.A., cuya carga transportada en 2018 fue de 1,1 millones de Tn y Ferroviaria Oriental S.A., que transportó 2,4 millones el mismo año. Un año antes, con 1,89 millones de Tn transportadas, el $42 \%$ fue de soja y derivados, el $20 \%$ hidrocarburos, $15 \%$ cemento y $11 \%$ siderúrgicos ${ }^{25}$.

Perú cuenta con cuatro empresas ferroviarias, la principal, Southern Copper Corp, transportó casi el 50\% de las 10.496.981 millones de toneladas de carga del 2017, el resto se repartía entre Ferrovías Central Andina S.A. y Ferrocarril Transandino, el Ferrocarril Huancayo-Huancavelica sólo aportó $2.202 \mathrm{Tn}^{26}$.

Finalmente, un aspecto a remarcar es que tanto Colombia como Paraguay no tenían en 2018 servicios ferroviarios (ver Figura 4).

\subsection{Los organismos internacionales de crédito y la integración regional}

En la sección anterior identificamos a IIRSA/COSIPLAN como el centro de las políticas de infraestructura y transporte en Sudamérica. Sin embargo, su lugar es preponderante, sobre todo, por el entramado político que se encuentra detrás. La lectura geopolítica que proponemos implica la participación de otro actor clave: el Banco Interamericano de Desarrollo. Esta entidad crediticia internacional, con sede en la capital de Estados Unidos, Washington D.C., es una de los principales prestamistas para infraestructura en la región. Desde la década de 1960 se han especializado en la

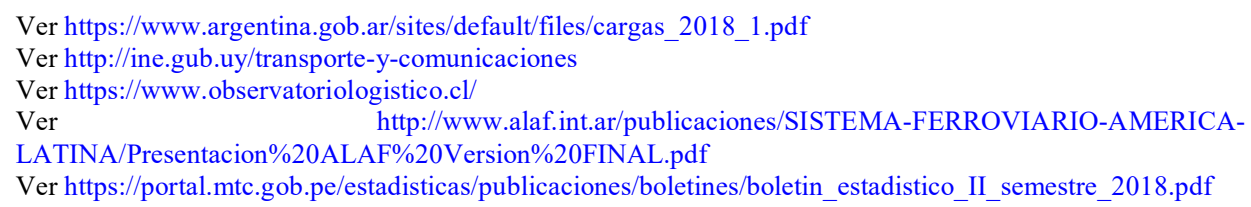


acción política para la eliminación de las barreras al comercio (barreras legales, técnicas y territoriales).

En el acto de inauguración del Instituto para la Integración de América Latina (INTAL) del BID en el año 1965, el entonces ministro de economía argentino, Juan Carlos Pugliese, señalaba que era necesario impulsar la integración a través de la Asociación Latinoamericana de Libre Comercio (ALALC), el BID y el Mercado Común Centroamericano. En aquella ocasión, el presidente del BID, Felipe Herrera, señalaba:

No olvidemos que nuestros sistemas económicos fueron, desde la época colonial, de "periferia". Y de periferia en un doble sentido: para los centros económicos que tradicionalmente se han abastecido en América Latina y para nuestros propios países, en que su vida económica más intensa sólo tuvo lugar en función de un comercio de exportaciones, generalmente radicado en las regiones cercanas al mar, y sin cohesión con las zonas interiores. Esas economías periféricas han vivido proyectadas tradicionalmente hacia el exterior, desconectadas entre ellas, separadas por factores geográficos y sin una infraestructura de transportes y de comunicaciones que las acerque (BID-INTAL, p.39).

Estas frases pueden ser interpretadas en una época donde las perspectivas desarrollistas y la Teoría de la Dependencia eran la principal influencia socio-económica en la región. En esa línea, el Presidente del BID buscaba tender puentes entre desarrollo e integración regional en tanto progreso para las mayorías a través de la industria, de la interconexión nacional, la complementación y la coordinación.

En 1978, con un contexto de dictaduras militares en todos los países del continente con la excepción de Venezuela, el organismo presentaría una línea que comenzaba a alejarse de la necesidad de inversiones en transporte que favorezcan el industrialismo para retomar las actividades extractivas y primarias como eje del desarrollo económico en la región: "esta presencia de las actividades mineras y agropecuarias, se proyecta de manera decisiva sobre los sistemas de transporte, por cuanto sus producciones normalmente de gran magnitud, requieren de instrumentos aptos para mover esas cargas en condiciones económicas adecuadas" (BID-INTAL, p.16). En ese mismo informe, el BID-INTAL ya señalaba que el futuro ferroviario estaba en el tráfico de cargas a granel agropecuarias y mineras competitivas en los mercados internacionales.

Luego de años de intercambios, el BID-INTAL publicó en 1980 el informe final sobre la "Red Fundamental de Transporte del Cono Sur" presentada originalmente en 1977. En aquella ocasión los Ministros de Obras Públicas y Transporte de los países implicados concluían nueve años de debates acerca de cuáles obras de infraestructura de transporte debían ser priorizadas. El texto buscaba apoyo político conjunto para financiar e iniciar dichas obras. Este informe remarcaba la necesidad de que cada modo de transporte fuese utilizado según su rol "dado" (BID-INTAL, 1980).

La década de 1990 mostró al BID, al igual que todos los organismos internacionales de la región, celebrando la apertura comercial. Por el lado positivo, la liberalización favoreció a la mayoría de los países gracias a notables aumentos de la productividad. "Los resultados del crecimiento son espectaculares; sin la liberalización, el ingreso per cápita de la región habría aumentado, en promedio, un $30 \%$ a un $40 \%$ 
menos, resultado que rara vez se da en el caso de otras políticas públicas" (Moreno, 2019, p.xx).

El informe del BID del 2005, escrito por Vito Tanzi, expresa de manera clara la política de este organismo en relación a la necesidad de la construcción de infraestructura de transporte, particularmente internacionales, para el desarrollo de la región. En las conclusiones se presenta el interés del BID por invertir en infraestructura regional: "El desarrollo de relaciones económicas y comerciales entre Estados soberanos pertenecientes a una misma región puede llegar a ser un importante objetivo político para los países relevantes" (Tanzi, 2005, p.21). Es válido interpretar que, dado que Estados Unidos posee el 30\% de los votos en el BID, por países relevantes, el autor hace referencia a los intereses de la política exterior norteamericana:

En realidad la creación del BID fue promovida por los Estados Unidos que, en pleno apogeo de la Guerra Fría y de los movimientos revolucionarios latinoamericanos, pretendía reforzar sus relaciones con América Latina y crear nuevos mecanismos de promoción del desarrollo para contrarrestar las crecientes amenazas al orden establecido y a la hegemonía estadounidense en la región (Munich i Gasa, 1998, p.91).

También, el Banco Mundial (BM) ha participado de reuniones del IIRSA/COSIPLAN. Por ejemplo, en la Reunión del GTIF de Montevideo de 2014, el BM presentó el informe "Desafío y Oportunidades en la Integración Ferroviaria". Este informe comienza con un mapa rudimentario que se encuentra en circulación en Internet desde hace varios años, denominado "Red ferroviaria de Sudamérica". En este mapa se identifican las diversas trochas, los ferrocarriles transfronterizos y algunos proyectos a futuro. El informe remarca como necesidad principal que las conexiones ferroviarias ayuden a transportar desde el centro del continente hacia los puertos "por un lado u otro" haciendo referencia a los océanos ${ }^{27}$.

La CAF por su parte ha financiado una serie de estudios para justificar las inversiones ferroviarias orientadas a la exportación de materias primas. Uno de los más significativos fue encargado a Jorge Kogan (2004) quien en las conclusiones señalaba el uso recomendado para los ferrocarriles de la región:

a) Brasil es uno de los principales productores y exportadores de mineral de hierro y Chile y otros países andinos lo son tanto de minerales metalíferos como no metalíferos; b) Argentina y Brasil han estado mejorando su posición en el mercado internacional de granos, junto con otros países productores como Bolivia y Paraguay; c) resulta esperable que la actividad del carbón en Colombia mantenga, al menos, el nivel de importancia revelado hasta el momento; y d) el conjunto de estas actividades productivas representan una gran parte del PBI de la mayoría de los países de la región (Kogan, 2004, p.282).

En 2011, Néstor H. Roa Jefe de División División de Transporte del BID, expresaba:

27 Ver http://www.iirsa.org/admin_iirsa_web/Uploads/Documents/if_montevideo14_presentacion_BM.pdf 
Por primera vez en mucho tiempo la región presenta un importante número de proyectos ferroviarios, y por primera vez en mucho tiempo estos proyectos suponen la mejora y expansión de las redes de carga. Los proyectos que se están analizando y, en algunos casos, construyendo tienen un sólido sustento productivo y económico, y seguramente representarán adiciones a las redes que, además de atender a los mercados para los cuales fueron desarrollados, permitirán atraer nuevas demandas que expandirán el uso del modo ferroviario (Kohon, 2011, p.12).

El informe de Kohon remarcaba que entre 1999 y 2008 (incluyendo a México), el tráfico de cargas por ferrocarril había aumentado $59 \%$ en su tonelaje total y que la ampliación a nuevos proyectos, en el marco de IIRSA/COSIPLAN, dependía, sobre todo de los flujos internacionales más que con los tráficos interoceánicos (Kohon, 2011).

Perry y García (2011), aportan una mirada interesante sobre el vínculo entre los organismos multilaterales y los países latinoamericanos. Los autores remarcan que durante la década de 1990, tanto el Banco Mundial como el BID confiaron en que las reformas neoliberales de los Estados, producto del Consenso de Washington, conducirían al reemplazo de la inversión pública por privada.

El recorrido por los organismos muestra que, sobre todo el BID, funcionó en espejo a los contextos políticos de la región. Durante la década de 1960 acompañó los proyectos industrialistas y desarrollistas para luego ir trasladándose a posiciones asociadas al libre comercio y la inserción internacional a través de la exportación de materias primas como política de desarrollo. Queda abierta la pregunta de si la interacción entre este organismo internacional y los Estados fue un elemento que colaboró con el abandono de la perspectiva de la inversión para el fortalecimiento de los mercados internos y la industria.

\section{Conclusiones}

De lo analizado previamente se pueden extraer dos conclusiones. En primer lugar y respondiendo a la pregunta inicial, notamos la existencia de una concordancia entre actores políticos involucrados nacionales y multilaterales en que la ecuación + ferrocarriles $=+$ desarrollo es una fórmula válida. Esta lógica se encuentra presente en los gobiernos de la región desde el período estudiado, en los organismos multilaterales de crédito y en las organizaciones multilaterales - que dependen de los poderes ejecutivos, pero también desarrollan un pensamiento autárquico-, lo que conlleva a que sea un tema de poca participación en la agenda pública.

En esa línea, observamos como los estudios académicos, los informes institucionales y los discursos políticos no logran profundizar en relación a los efectos que tales infraestructuras pueden tener. Es posible considerar a las Agendas Prioritarias de Inversión, los corredores bioceánicos, los Ejes de Desarrollo promovidos por IIRSA/COSIPLA como el soporte material a un modelo de desarrollo económico que permite una inserción internacional competitiva para la región pero también resulta limitante para una expansión del bienestar en tanto las actividades productivas privilegiadas son de bajo valor agregado. Este proceso ya se ha visto en el siglo XIX con la construcción original de los ferrocarriles y su uso para llevar materias primas hacia los puertos de ultramar. El peligro con la infraestructura planeada es la 
reproducción de aquel modelo de acumulación que significó, para América del Sur, una condena al subdesarrollo.

La constante vinculación a la idea de desarrollo como una panacea se presenta como constante desde hace décadas y todos los gobiernos e instituciones multilaterales parecen sucumbir frente al canto de sirenas que significan los proyectos de infraestructura de transporte regional y, sobre todo, los ferroviarios.

En segundo lugar, consideramos que la lectura de geopolítica de baja intensidad resulta apropiada en tanto permite vincular las perspectivas territoriales que los actores políticos buscan concretar con la infraestructura ferroviaria, planteada como sinónimo de desarrollo, sobre la base de un proyecto político que involucra la producción económica y los vínculos comerciales con el mundo. En esa línea, a lo largo del trabajo hemos documentado como las organizaciones internacionales (MERCOSUR, IIRSA) y sus burocracias producen informes y proyectos que muchas veces representan posiciones opuestas a las declamadas por los gobiernos nacionales en tanto los usos y resultados posibles de esas infraestructuras. También hemos mostrado que los procesos de integración regional que, a pesar del énfasis político, a partir de los llamados gobiernos de izquierda, en la región, en el período 2002-2015, los avances reales en términos de infraestructura, políticas de desarrollo común, articulaciones en transporte internacional, han sido escasas.

A futuro queda entonces explorar la lógica de funcionamiento interno de las instituciones regionales a nivel de funcionarios técnicos y políticos de segundo nivel para entender si estos dispositivos resultan efectivos para encarar las políticas acordadas a nivel de jefatura de Estado.

\section{Agradecimientos}

El autor agradece los comentarios de Dhan Zunino Singh y Alejandro Benedetti.

\section{Referencias}

Benedetti, A. (2005). El ferrocarril Huaytiquina, entre el progreso y el fracaso. Aproximaciones desde la geografía histórica del Territorio de Los Andes. Revista Historia, (4), 123165.

Benedetti, A. (2011). Territorio: concepto integrador de la geografía contemporánea. En P. Souto (Coord.), Territorio, Lugar, Paisaje. Prácticas y conceptos básicos en geografía (pp. 11-82). Buenos Aires: Facultad de Filosofia y Letras UBA.

Bernal-Meza, R. (2010). International Thought in the Lula Era. Revista Brasileira de Politica Internacional, 53(núm. Especial), 193-213.

Blanco, J. (2018). Redes. En D. Zunino Singh, G. Guicci y P. Jirón (Eds.), Términos clave para los estudios de movilidad en América Latina (pp. 153-160). Buenos Aires: Biblos.

Briceño Ruiz, J. (2013). Ejes y modelos en la etapa actual de la integración eco-nómica regional en América Latina. Estudios Internacionales, 45(175), 9-39.

BID-INTAL (1965). Instituto para la integración de América Latina. Buenos Aires: BIDINTAL. 
BID-INTAL (1978). Infraestructura y Servicios en la Integración de América Latina. Buenos Aires: BID-INTAL.

BID-INTAL. (1980). Red Fundamental de Transporte del Cono Sur. Buenos Aires. Buenos Aires: BID-INTAL.

CEPAL. (1972). Ferrocarriles internacionales de Sudamérica y la integración económica regional. Nueva York: Naciones Unidas.

García Linera, Á. (2017). Espacio nacional y espacio global del capitalismo. Geopolítica(s), $8(2), 159-176$.

Gardini, G. L. (2015). Towards modular regionalism: the proliferation of Latin American cooperation. Revista Brasileira de Politica Internacional, 58(1), 210-229.

González Pizarro, J.; Lufin Varas, M., y Galeno Ibaceta, C. (2014). Británicos en la región de Antofagasta. Los negocios concomitantes con la minería del desierto de Atacama y sus redes sociales (1880-1930). Estudios Atacameños. Arqueología y Antropología Surandinas, (48), 175-90.

Inostroza Fernández, L., y Bolivar Espinoza, A. (2004). Corredores bioceánicos: Territorios, políticas y estrategias de integración subregional. Análisis Económico, 19(41), 153-174.

IIRSA/COSIPLAN. (2017). Insumos para Elaborar una Estrategia que Facilite la Integración Ferroviaria de Suramérica. Recuperado de http://www.iirsa.org/admin_iirsa_web/Uploads/Documents/Anexo3_InsumosParaEstrategia_Integraci $\% \mathrm{C} 3 \% \mathrm{~B} 3 \mathrm{nFerroviariaSuram} \% \mathrm{C} 3 \% \mathrm{~A} 9 \overline{\text { rica.pdf }}$

Kogan, J. H. (2004). Rieles con futuro: Desafios para los ferrocarriles de América del Sur. Caracas: CAF.

Kohon, J. (2011). Más y mejores trenes Cambiando la matriz de transporte en América Latina y el Caribe. Buenos Aires: BID-INTAL.

Krüger, R. (2018). Transporte. En D. Zunino Singh, G. Guicci y P. Jirón (Eds), Términos clave para los estudios de movilidad en América Latina (pp.179-186). Buenos Aires: Biblos.

Lacoste, P. (2013). El ferrocarril transandino. Santiago de Chile: Editorial Idea.

Manzanal, M. (2010). Desarrollo, poder y dominación. Una reflexión en torno a la problemática del desarrollo rural en Argentina. En M. Manzanal y F. Villarreal (Orgs.), El desarrollo y sus lógicas en disputa en territorios del norte argentino (pp.17-44). Buenos Aires: Ediciones Ciccus.

Moreno, L. A. (2019). Prólogo. En M. M. Moreira y E. Stein (Comps.), De promesas a resultados en el comercio internacional: lo que la integración global puede hacer por América Latina y el Caribe (pp. xix-xxii). BID.

Munich i Gasa, J. (1998). Las instituciones multilaterales de financiación del desarrollo. Afers Internacionals, (40-41), 77-108.

Preciado Coronado, J., y Uc, P. (2010). La construcción de una geopolítica crítica desde América Latina y el Caribe. Hacia una agenda de investigación regional. Geopolítica(s), 1(1), 65-94.

Perry, G., y García, E. (2017). The Influence of Multilateral Development Institutions on Latin American Development Strategies. International Develompent Policy, (9), 199231. https://doi.org/10.4000/poldev.2367

Quagliotti de Bellis, B. (1981). Geopolítica e integración sudamericana. En L. Dallanegra Pedraza, T. de Castro, H. M. Balmaceda y B. Quagliotti de Bellis, Geopolítica y relaciones internacionales (pp.95-118). Buenos Aires: Pleamar. 
Rascovan, A. (2014). MERCOSUR, integración regional y dinámicas transfronterizas: el caso del ferrocarril internacional en la frontera argentino-brasileña. Tesis de Doctorado. Universidad de Buenos Aires, Argentina.

Rascovan, A. (2016). La infraestructura y la integración regional en América del Sur. Una visión geopolítica de los proyectos ferroviarios en el marco de IIRSA-COSIPLAN. Relaciones Internacionales, 26(51), 59-80.

Rascovan, A. (2017). International Railways in Argentina: Rethinking International Relations and Regional Integration Studies in the Southern Cone. Mobility in History, 8, $147-$ 156.

Riggirozzi, P., y Tussie, D. (2012). The Rise of Post-Hegemonic Regionalism. En P. Riggiorizzi y D. Tussie (Eds.), The Rise of Post-Hegemonic Regionalism: The case of Latin America (pp.1-16). Nueva York: Springer.

Rivarola Puntigliano, A. (2010). El nacionalismo continentalista en Latinoamérica. Anales Nueva Época, (12), 165-197.

Rivarola Puntigliano, A. (2013). El retorno de la geopolítica: una perspectiva sudamericana. En I. Sarti, D. Perrotta, M. Leite Lessa y G. Cardoso Carvalho (Eds.), Por uma integracão ampliada do América do Sul no século XXI (pp. 441-466). Rio de Janeiro: Perse.

Rivarola Puntigliano, A. (2016). 21st century geopolitics: integration and development in the age of "continental states". Territory, Politics, Governance, 5(4), 478-494.

Rückert, A. A., y Pereira Carneiro, C. (2018) Políticas territoriais na América do Sul: infraestruturas de conexão e repercussões em regiões periféricas. En A. Rückert, A. C. P. da Silva y G. de V. Silva (Orgs.), Geografia Política, Geopolitica e Gestão do Território: integração sul-americana e regiões periféricas (pp. 11-39). Porto Alegre: Editora Letra1.

Sanahuja, J. A. (2012). Post-liberal Regionalism in South America: The Case of UNASUR (RSCAS working paper 2012/05). Florencia: European University Institute.

Santos, M. (1996). A natureza do espaço. Ténica e tempo. Razão e emoção. San Pablo: HUCITEC.

Schteingart, D., y Coatz, D. (2015). ¿Qué modelo de desarrollo para la Argentina? Boletín Informativo TECHINT, (349), 49-88.

Setelich, J. (2013). El ferrocarril como herramienta de promoción de la productividad y la competitividad: el caso de AFE. En D. Chavez y S. Torres (Eds.), La reinvención del Estado. Empresas públicas y desarrollo en Uruguay, América Latina y el mundo (pp.213222). Montevideo: Transnational Institute, ANTEL y MIEM-DNI.

Swyngedouw, E. (2004). Globalisation or "glocalisation"? Networks, territories and rescaling. Cambridge Review of International Affairs, 17(1), 25-48.

Tanzi, V. (2005). Building regional infrastructure in Latin America. Buenos Aires: BIDINTAL.

Thomson, I. (1995). Los ferrocarriles y su contibrución al comercio internacional. Buenos Aires: BID-INTAL.

Vázquez López, R. (2011). Economic integration in Latin America: the theoretical Vision of ECLAC against the evolution project in the region. Journal of Economics, Finance and Administrative Science, 16(31), 107-118.

Vitte, C. de C. S. (2013). Geopolítica e relações internacionais: as organizações de integração regional na América Latina. Meridiano - Revista de Geografia, (2), 31-52

Vitte, C. de C. S. (2014). Geopolítica e geoeconomia dos recursos hídricos na América do Sul: algumas considerações para a discussão sobre integração regional. Revista de Geografia (UFPE), 31(2), 205-225. 
Vitte, C. de C. S. (2018). Integração da infraestrutura produtiva na América do Sul sob a coordenação do Cosiplan/Unasul: financiamento e planejamento territorial. En A. Rückert, A. C. P. da Silva y G. de V. Silva (Orgs.), Geografia Política, Geopolítica e Gestão do Território: integração sul-americana e regiões periféricas (pp. 51-67). Porto Alegre: Editora Letra1.

Wallerstein, I. (2006). Después del desarrollismo y la globalización, ¿qué? Polis, (13). Recuperado de http://journals.openedition.org/polis/5405.

\section{Otros sitios consultados:}

https://www.perfil.com/noticias/politica/-20110829-0032.phtml

https://es.wikipedia.org/wiki/Tren_de_los_Pueblos_Libres

http://www.abc.com.py/nacionales/acuerdos-entre-cartes-y-pinera-618787.html

https://www.eltribuno.com/jujuy/nota/2017-6-22-12-39-0-apertura-del-seminario-

ferrocarril-para-la-integracion

https://es.wikisource.org/wiki/Tratado_de_Paz_y_Amistad_entre_Chile_y_Bolivia

https://www.argentina.gob.ar/sites/default/files/cargas_2018_1.pdf

http://ine.gub.uy/transporte-y-comunicaciones

https://www.observatoriologistico.cl/

http://www.alaf.int.ar/publicaciones/SISTEMA-FERROVIARIO-

AMERICALATINA/Presentacion\%20ALAF\%20Version\%20FINAL.pdf

https://portal.mtc.gob.pe/estadisticas/publicaciones/boletines/boletin_estadistico_II_semestr e_2018.pdf

\section{Siglas:}

AGN: Auditoría General de la Nación (Argentina)

ALADI: Asociación Latinoamericana de Integración

ALALC: Asociación Latinoamericana de Libre Comercio

ALBA-TCP: Alianza Bolivariana para los Pueblos de Nuestra América - Tratado de Comercio de los Pueblos

ALL: América Latina Logística

API: Agenda Prioritaria de Inversión

BID: Banco Interamericano de Desarrollo

CAF: Corporación Andina de Fomento

CEBAC: Comisión Especializada Brasileño Argentina de Cooperación

GMC: Grupo Mercado Común

COSIPLAN: Consejo Suramericano de Planificación

EID: Ejes de Inversión y Desarrollo

FONPLATA: Fondo Financiero para el Desarrollo de los Países de la Cuenca del Plata

FCU: Ferrocarril Central del Uruguay

GTIF: Grupo de Trabajo sobre Integración Ferroviaria

IIRSA: Iniciativa para la Infraestructura Regional Suramericana

INTAL: Instituto para la Integración de América Latina

MERCOSUR: Mercado Común del Sur 
OEA: Organización de los Estados Americanos SPRC: The São Paulo Railway Company

UNASUR: Unión de Naciones Suramericanas 